\title{
SISTEM INFORMASI GEOGRAFIS TITIK RAWAN KECELAKAAN DAERAH SUMATERA BARAT BERBASIS WEB
}

\author{
Ilfa Stephane ${ }^{1}$, Heru Saputra ${ }^{2}$, Karfindo ${ }^{3}$, Silis Jelita ${ }^{4}$ \\ 1ilfastephane@gmail.com, ${ }^{2 h} 3$ ru.saputra@gmail.com, ${ }^{3}$ karfindo@stmikindonesia.ac.id, \\ ${ }^{4}$ silsijelita@gmail.com \\ 1,2,3,4 STMIK Indonesia Padang
}

\begin{abstract}
Abstrak
Sistem Informasi Geografis (SIG) merupakan sistem yang dirancang untuk bekerja dengan data yang tereferensi secara spasial atau koordinat-koordinat geografis. Menurut data yang dimiliki Direktorat Lalu Lintas Polda Sumbar, jumlah daerah rawan kecelakaan di Sumatera Barat terdapat 48 titik. Hal ini menyebabkan dibutuhkannya sebuah Sistem Informasi Geografis daerah rawan kecelakaan di Sumatera Barat berbasis web untuk menggambarkan peta lokasi daerah rawan beserta informasi yang dibutuhkan. Aplikasi Sistem Informasi Geografis Daerah Rawan Kecelakaan Berbasis Web, dengan bahasa pemograman (JavaScript dan PHP), MySql sebagai basis data dan Google Maps Api. Hasil akhir dari penelitian ini adalah terciptanya aplikasi SIG berbasis web yang dapat menyajikan informasi lokasi daerah rawan kecelakaan di Sumatera Barat secara terinci dan dapat diakses dengan mudah oleh masyarakat.
\end{abstract}

Kata kunci: SIG, Web, Kecelakaan

\begin{abstract}
Geographic Information System (GIS) is a system designed to work with spatially-referenced data or geographic coordinates. According to data owned by Traffic Directorate of West Sumatra Police, the number of accident-prone areas in West Sumatra is 48 points. This leads to the need for a Geographic Information System of accident-prone areas in West Sumatra based on the web to describe the map of vulnerable area locations along with the information needed. Geographic Information System Application of Web-Based Accident Complex, with programming languages (JavaScript and PHP), MySQL as database and Google Maps API. The result of this research is the creation of a web-based GIS application that can present information about the location of accident-prone areas in West Sumatra in detail and can be accessed easily be used people.
\end{abstract}

Keywords: SIG, Web, Accident

\section{Pendahuluan}

Perkembangan teknologi informasi yang begitu pesat berpengaruh terhadap semua aspek, salah satunya teknologi sistem informasi geografis. Sistem Informasi Geografis (SIG) merupakan gabungan tiga unsur pokok: sistem, informasi, dan geografis. Dengan demikian, pengertian terhadap ketiga unsur pokok ini sangat membantu dalam memahami sistem informasi geografis. Dengan melihat unsur-unsur pokoknya, maka jelas bahwa sistem informasi geografis juga merupakan tipe sistem informasi, tetapi dengan unsur "Geografis". Jadi, sistem informasi geografis merupakan sistem yang menekankan pada unsur "informasi geografis" [1].

Sistem Informasi Geografis, atau dalam Bahasa Inggris lebih dikenal dengan Geographic Information System adalah suatu sistem berbasis komputer yang digunakan untuk mengelolah dan menyimpan data atau informasi yang bereferesi geografis [2]. Web GIS adalah sistem informasi geografis yang didistribusikan di seluruh lingkungan jaringan komputer untuk mengintegrasikan, menyebarkan, dan mengkomunikasikan informasi geografis secara visual di World Wide Web melalui internet [3]. SIG sudah digunakan secara luas untuk mengakses informasi tentang suatu lokasi [4].

Sumatera Barat adalah salah satu provinsi di Indonesia yang terletak di pulau Sumatera dengan Padang sebagai ibu kotanya. Sesuai dengan namanya, wilayah provinsi ini menempati sepanjang pesisir barat Sumatera bagian tengah, dataran tinggi Bukit Barisan di sebelah timur, dan sejumlah pulau di lepas pantainya seperti Kepulauan Mentawai. Dari utara ke selatan, provinsi dengan wilayah seluas $42.297,30 \mathrm{~km}^{2}$ ini berbatasan dengan empat provinsi, yakni Sumatera Utara, Riau, Jambi, dan Bengkulu. Sumatera Barat merupakan daerah yang memiliki tingkat kecelakaan yang besar, karena daerah jalanan yang ada memiliki kelokan yang banyak dan terjal contoh nya kelok Sembilan dan empat empat yang terdapat di daerah maninjau dan masih banyak lagi kelokan di daerah lainnya. Umumnya kecelakaan terjadi diakibatkan oleh truk, mobil pribadi dan tronton dikarenakan kurang memahami jalan di daerah tersebut. 
Badan Pusat Statistik mencatat bahwa angka kecelakaan lalu lintas yang terjadi di Indonesia masih tinggi seiring dengan pertumbuhan jumlah kendaraan bermotor yang sangat pesat dan arus lalu lintas yang padat, data terbaru yang dikeluarkan World Health Organization (WHO) menunjukkan Indonesia menempati urutan kelima negara dengan jumlah kematian terbanyak akibat kecelakaan lalu lintas. Pada 2010 jumlah korban meninggal sebanyak 31.234, dan pada 2013 karena adanya rencana umum nasional keselamatan, nilai kecelakaan lalu lintas turun menjadi 26.484, namun angka tersebut masih cukup tinggi (Republika, 2014). Kecelakaan melibatkan berbagai jenis kendaraan bermotor, terjadi diberbagai jenis jalan, dan melibatkan pelaku/korban dari berbagai usia. Angka kecelakaan yang terus meningkat membuat semua pihak merasa perlu untuk dilakukan langkah-langkah pencegahan. Agar kebijakan yang dihasilkan relevan dengan permasalahan yang dihadapi dalam upaya menurunkan angka kecelakaan, maka kebijakan tersebut harus didukung dengan informasiinformasi yang berasal dari data-data kecelakaan yang selama ini sudah terjadi [5]. Hasil Riskedas 2013 dan sesuai data yang dihimpun Dinas Perhubungan dan Komunikasi Informasi Sumatera Barat pada tahun 2015 tercatat 2157 kecelakaan lalulintas, hal ini menurun jika dibandingkan dengan kejadian tahun 2014 dengan 2625 kasus kecelakaan. Kota Padang merupakan angka tertinggi dengan 540 kejadian, disusul Kabupaten Padang Pariaman 315 kejadian dan Kota Pariaman 279 kejadian [6].

Dengan adanya kemajuan teknologi khususnya pada SIG dapat diterapkan dalam mengatasi masalah daerah rawan kecelakan lalu lintas, yaitu titik daerah rawan kecelakan lalu lintas yang ada di Sumatera Barat tepatnya, sehingga dapat membantu mengurangi tingkat kecelakaan yang terjadi dengan menggunakan handphone. Masyarakat juga dapat mencari informasi tentang daerah-daerah rawan kecelakaan lalu lintas yang akan dilalui, supaya mereka dapat meningkatkan kewaspadaan diri dalam berkendaraan di jalan raya. Dengan mengetahui letak lokasi dan daerah rawan kecelakaan lalu lintas diharapkan pengemudi lebih meningkatkan kewaspadaan dan lebih berhati-hati ketika melewati daerah tersebut, sehingga kecelakaan lalu lintas dapat diminimalisir.

Tujuan penelitian ini adalah mengembangkan aplikasi SIG untuk membantu masyarakat yang ingin melakukan perjalanan ke Sumatera Barat maupun keluar dari Sumatera Barat, sedangkan manfaatnya adalah dengan diterapkannya SIG memudahkan kegiatan pemetaan kecelakaan yang terjadi di daerah sumatera barat.

\section{Metode Penelitian}

Jenis penelitian yang dilakukan berupa penelitian kualitatif dengan data berupa informasi lokasi rawan kecelakaan pada setiap kabupaten serta data Polres dan Polresta yang ada di Sumatera Barat. Data diperoleh dari Direktorat Lalu Lintas Polda Sumbar seperti yang dijelaskan pada Tabel 1 . Metode penelitian yang digunakan mencakup analisis masalah, perancangan sistem, dan usulan implementasi.

Tabel 1. Data Daerah Rawan Kecelakaan

\begin{tabular}{|l|l|l|}
\hline No & \multicolumn{1}{|c|}{ Satuan Wilayah } & \multicolumn{1}{c|}{ Rawan Kecelakaan } \\
\hline 1 & Polresta Padang & $\begin{array}{l}\text { a. Jl. Adinegoro Lubuk Buaya Km 20 } \\
\text { b. Sepanjang Jalan By Pass Km 10 } \\
\text { c. Jl. Pdg - Solok Ladang Kadi Km 13 dan Km 23 } \\
\text { d. Jl. Bungus Teluk Kabung Km 15 }\end{array}$ \\
\hline 2 & $\begin{array}{l}\text { Polres Padang } \\
\text { Pariaman }\end{array}$ & $\begin{array}{l}\text { a. Jl. Umum Simpang Lubuk Pandan s/d sp. 3 Sicincin } \\
\text { b. Jl. Umum Pasar Lubuk Alung s/d Batang Tapakis. } \\
\text { c. Jl. Umum Talang Jala s/d Kampung Apar Kec. Batang Anai }\end{array}$ \\
\hline 3 & Polres Pessel & $\begin{array}{l}\text { a. Jl. Raya Siguntur Km 60 } \\
\text { b. Jl. Raya Api-Api Km 8 } \\
\text { c. Jl. Raya Painan - Kambang IV Koto Hilir Km 21 }\end{array}$ \\
\hline 4 & Polres Payakumbuh & $\begin{array}{l}\text { a. J. Soedirman } \\
\text { b. Jl. M. Hatta } \\
\text { c. Jl. A. Yani }\end{array}$ \\
\hline 5 & Polres Bukittinggi & $\begin{array}{l}\text { a. Tanjakan Kodok Kec. Palupuh Km 8, Kab. Agam } \\
\text { b. Penurunan Batagak Kec. Banuhampu, Sungai Puar, Agam Km 7, } \\
\text { c. Jl. Lurus Baso (Bukittinggi - Payakumbuh) Kec. Baso, Kab. Agam } \\
\text { Km 14, Km 17 dan Km 19 }\end{array}$ \\
\hline 6 & Polres Tanah Datar & $\begin{array}{l}\text { a. Jl. Umum Batu Limbak - Ombilin Km 23-24 } \\
\text { b. Jl. Umum Sungai Tarab Km 4-5 } \\
\text { c. Jl. Umum Ombilin - Batusangkar Km 8 }\end{array}$ \\
\hline 7 & Polres Pasaman & \begin{tabular}{l} 
a. Cengkeh Kec. Panti Km 35 \\
\hline
\end{tabular}
\end{tabular}




\begin{tabular}{|c|c|c|}
\hline & & b. Muara Manggung Kec. Lubuk Sikaping Km 4 \\
\hline 8 & Polres Solok Kota & $\begin{array}{l}\text { a. Jl. Lurus Sumani, Kacang } \\
\text { b. Nagari Bukittandang Km 8, Muara Panas }\end{array}$ \\
\hline 9 & Polres 50 Kota & $\begin{array}{l}\text { a. Jl. Raya Tanjung Pati Km } 5 \text { s/d Km } 20 \\
\text { b. Kelok } 9 \mathrm{Km} 21 \mathrm{~s} / \mathrm{d} \mathrm{Km} 25\end{array}$ \\
\hline 10 & $\begin{array}{l}\text { Polres Padang } \\
\text { Panjang }\end{array}$ & $\begin{array}{l}\text { a. Batu Badukung, Kec. X Koto, Kab. Tanah Datar. } \\
\text { b. Cubadak Bungkuk- Bukit Berbunga Padang Panjang } \\
\text { c. Kelok Hantu Aia Angek, Kec. X Koto, Kab. Tanah Datar. } \\
\text { d. Tanjung Mutiara, Kec. Batsel, Kab. Tanah Datar. }\end{array}$ \\
\hline 11 & Polres Sawahlunto & Jalan Lintas Sumatera antara Km 79 s/d Km 81 \\
\hline 12 & Polres Pariaman & $\begin{array}{l}\text { a. Sei Limau Km } 15 \\
\text { b. Kurai Taji Km } 8\end{array}$ \\
\hline 13 & Polres Solok Selatan & $\begin{array}{l}\text { a. Jl. Padang Aro Km } 166 \\
\text { b. Jl. Letter W } \\
\text { c. Sangir Batang Hari }\end{array}$ \\
\hline 14 & Polres Agam & $\begin{array}{l}\text { a. Jl. Umum Bawan Km } 15 \\
\text { b. JI. Tiku Km } 5\end{array}$ \\
\hline 15 & Polres Solok & Cupak, Kec. Gunung Talang Km 12, Km 18 dan Km 22 \\
\hline 16 & Polres Sijunjung & $\begin{array}{l}\text { a. Nagari Kunpar Km } 70 \text { dari Muaro Kec. Kamang Baru } \\
\text { b. Kec. IV Nagari Km } 12 \text { Dari Muaro }\end{array}$ \\
\hline 17 & $\begin{array}{l}\text { Polres Pasaman } \\
\text { Barat }\end{array}$ & $\begin{array}{l}\text { a. Simpang Empat Km. } 01 \mathrm{Kec} \text {. Pasaman } \\
\text { b. Padang Tujuh Km. } 8 \\
\text { c. Ujung Gading Km. } 25 \mathrm{~s} / \mathrm{d} 29\end{array}$ \\
\hline 18 & Polres Dharmasraya & $\begin{array}{l}\text { a. Jalan Lintas Sumatera Pulau Punjung Km } 184 \text { s/d } 186 \\
\text { b. Jalan Lintas Sumatera Sungai Dareh Km } 186 \mathrm{~s} / \mathrm{d} 190 \\
\text { c. Jalan Lintas Sumatera Koto Baru Km } 117 \mathrm{~s} / \mathrm{d} 202 \\
\text { d. Jalan Lintas Sumatera Sungai Rumbai Km } 226 \mathrm{~s} / \mathrm{d} 229\end{array}$ \\
\hline
\end{tabular}

(Sumber): Direktorat Lalu Lintas Polda Sumbar

\section{Hasil dan Pembahasan}

Google Maps adalah layanan gratis yang diberikan oleh Google dan sangat popular. Google Maps merupakan suatu peta dunia yang dapat digunakan untuk melihat suatu daerah. Dengan kata lain, Google Maps adalah suatu peta yang dapat dilihat dengan menggunakan suatu browser atau android. Kita dapat menambahkan fitur Google Maps kedalam web dan android yang telah dibuat karena Google Maps merupakan layanan yang besifat terbuka (Open Source) untuk pengembangan lebih lanjut.

\subsection{Pemanfaatan Peta Google Maps}

Ada beberapa hal yang harus dipahami untuk menampilkan peta wilayah tertentu, yaitu posisi garis bujur (Latitude) dan garis lintang (Longitude). Dengan menggunakan script pada Gambar 1, maka Peta Sumatera Barat dapat ditampilkan secara keseluruhan seperti pada Gambar 2 dengan Latitude -0.7399397 dan Longitude 100.8000051. Peta Sumatera Barat ditempatkan pada posisi center atau tengah dan ukuran peta yang dapat diperbesar 13 kali.

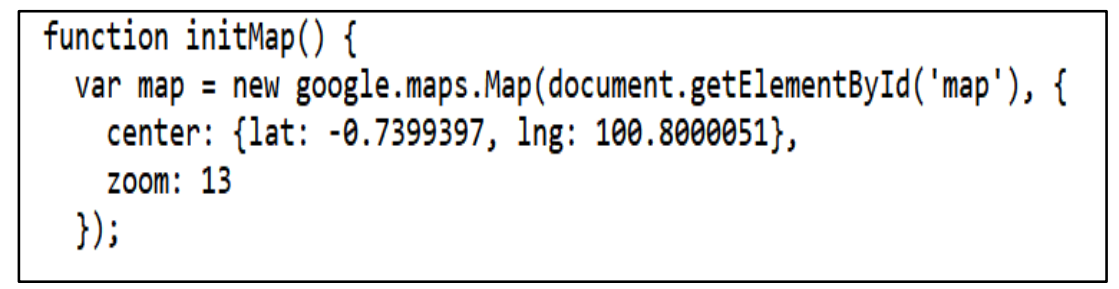

Gambar 1. Script Untuk Menampilkan Peta Sumatera Barat 


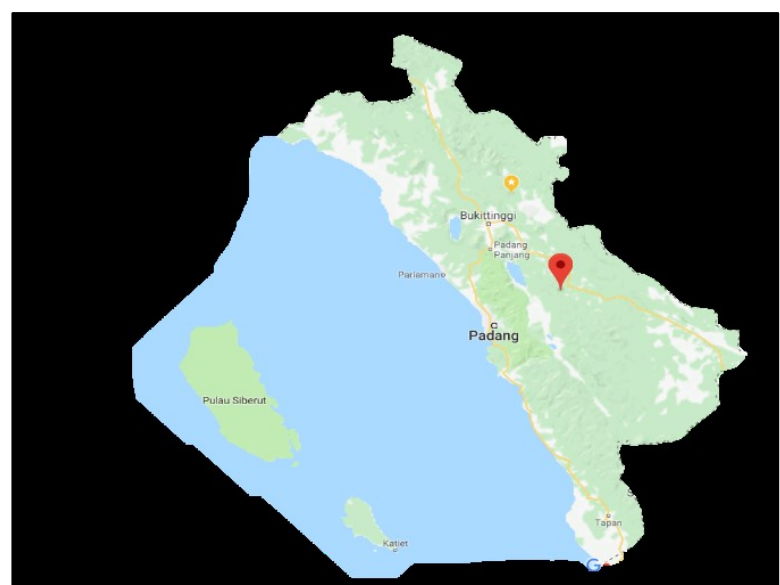

Gambar 2. Menampilkan Peta Sumatera Barat

\subsection{Implementasi pada Perangkat Lunak}

Tahap implementasi sistem pada perangkat lunak dilakukan untuk menyelesaikan rancangan sistem yang telah disetujui dan menguji sistem yang baru. Proses implementasi sistem pada perangkat lunak dimulai dari proses input daerah rawan kecelakaan di Sumatera Barat yang dilakukan oleh Polres masing-masing yang terdiri dari input data lokasi, sedangkan input data kabupaten, input data kecamatan, input data polres, dan input data user dilakukan oleh admin Direktorat Lalu Lintas Polda Sumbar. Proses implementasi selanjutnya akan menunjukkan titik rawan kecelakaan di daerah Sumatera Barat yang disajikan berupa peta, grafik, dan laporan perkabupaten serta menyajikan informasi lokasi Polres dan Polresta Sumatera Barat.

\section{Pencarian Daerah Rawan Kecelakaan Berdasarkan Posisi Pengguna}

Pengguna dapat mengetahui lokasi rawan kecelakaan dari jarak atau radius tertentu melalui menu Pencarian Daerah Rawan Kecelakaan Berdasarkan Posisi Pengguna seperti yang disajikan Gambar 3. Tanda hijau menandakan posisi pengguna sedangkan warna hitam menandakan lokasi rawan kecelakaan.

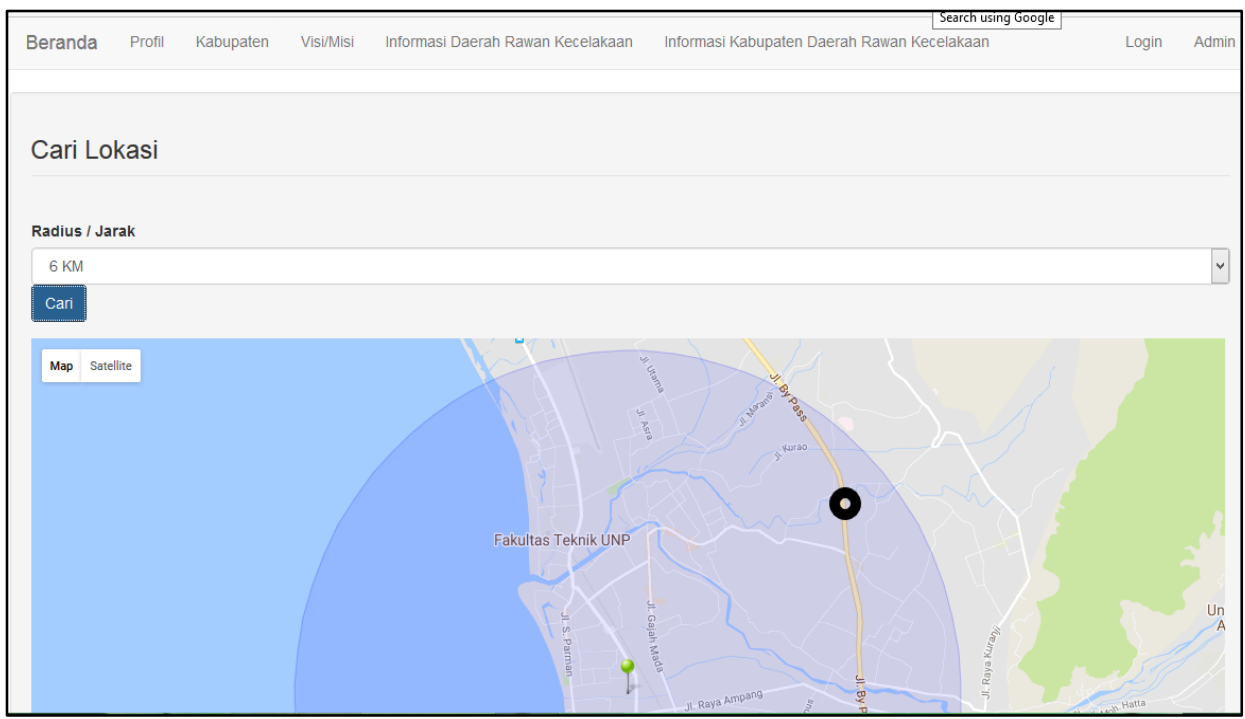

Gambar 3. Tampilan Pencarian Daerah Rawan Kecelakaan berdasarkan Posisi

2. Peta Daerah Rawan Kecelakaan

Pengguna

Menu ini menjelaskan peta informasi rawan kecelakan disetiap kabupaten Sumatera Barat. Pengguna dapat memanfaatkan tombol pencarian yang telah disediakan untuk mendapatkan informasi kabupaten mana yang menjadi titik rawan kecelakaan seperti pada Gambar 4. 


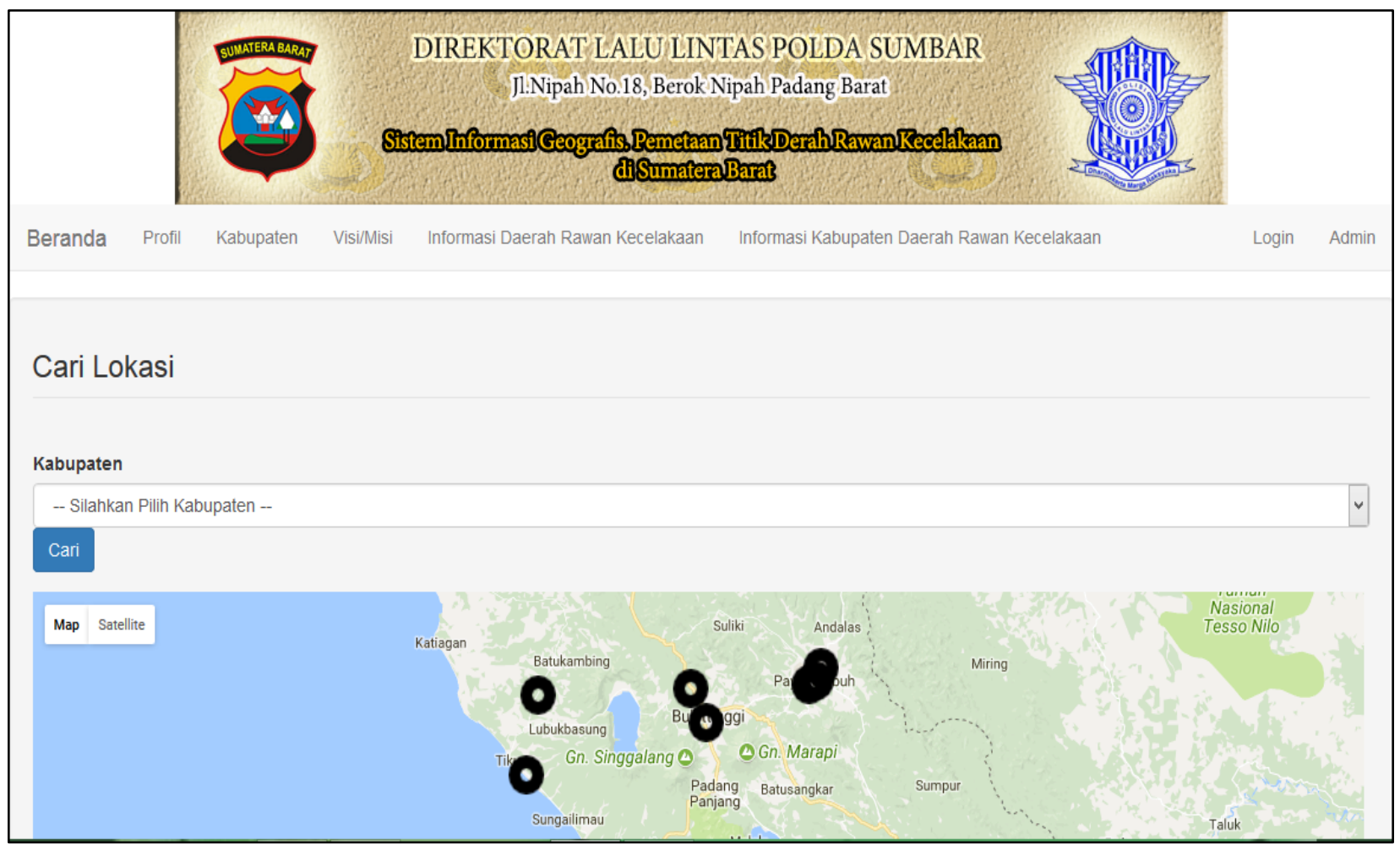

Gambar 4. Tampilan Peta Daerah Rawan Kecelakaan

3. Laporan Daerah Rawan Kecelakaan di Sumatera Barat Dalam Bentuk Grafik Laporan ini menggambarkan presentase daerah rawan kecelakaan di sumatera barat seperti pada Gambar 5.

Grafik Jumlah Lokasi Rawan Kecelakaan di Sumatera Barat

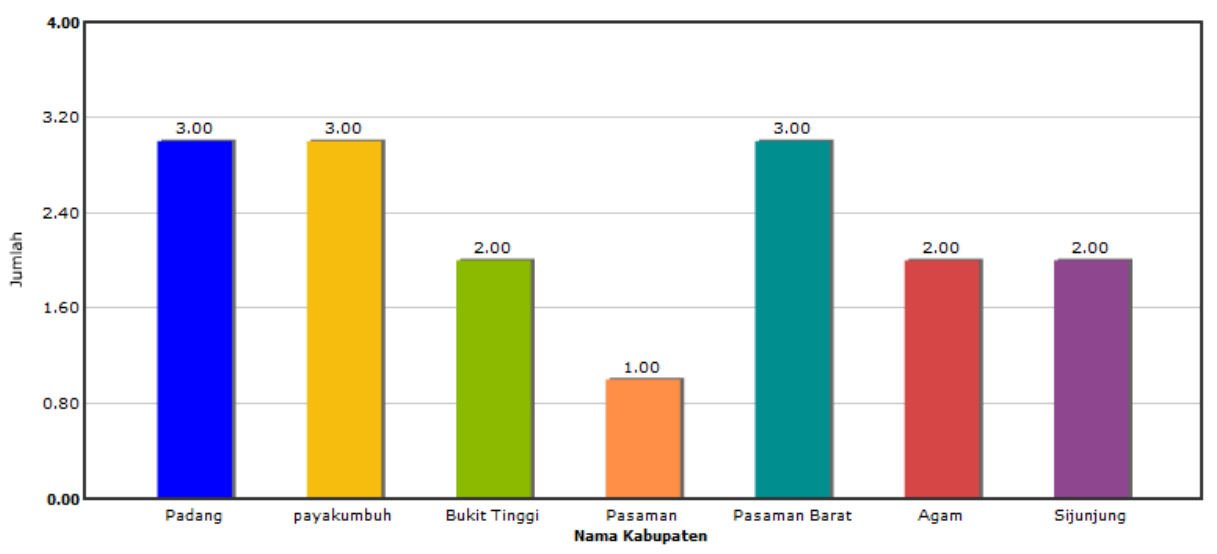

Gambar 5. Laporan Grafik

4. Laporan Kabupaten

Laporan ini berisikan data-data daerah rawan kecelakaan pada masing-masing kabupaten lengkap dengan informasi keterangan nama jalan, latitude dan longitude seperti pada Gambar 6. 


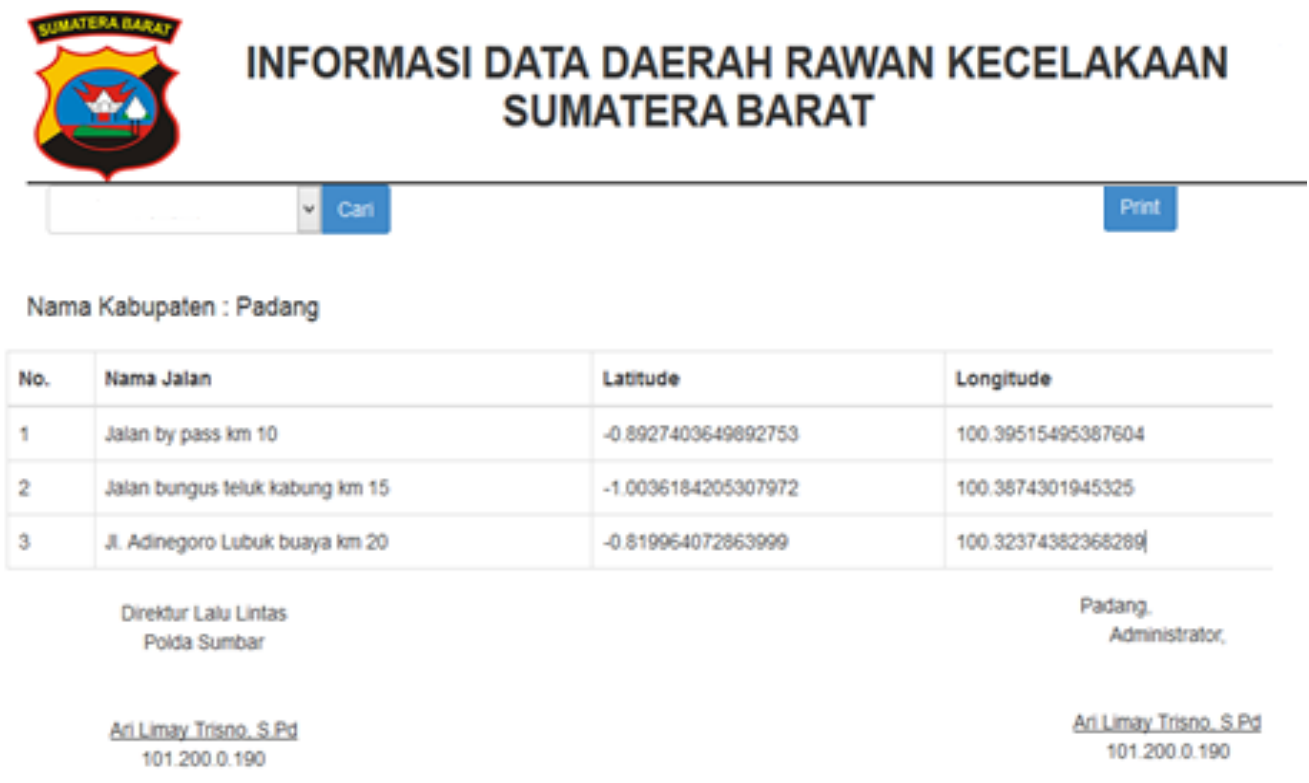

Gambar 6. Laporan Rawan Kecelakaan per Kabupaten

5. Laporan Polres dan Polresta

Laporan ini berisikan nama Polres dan Polresta yang ada di Sumatera Barat lengkap dengan informasi keterangan nama jalan, latitude dan longitude seperti pada Gambar 7.

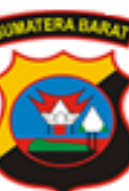

\section{INFORMASI DATA DAERAH RAWAN KECELAKAAN SUMATERA BARAT}

\begin{tabular}{|c|c|c|c|c|}
\hline No. & Nama Polres & Nama Jalan & Latitude & Longitudel \\
\hline 1 & Pasaman Timur & cengkeh pant & 0.321896257091707 & 100.06668046116829 \\
\hline 2 & Poirestra Padang & Jalan by pass km 10 & 0.8927403649992753 & 10039615496387604 \\
\hline 3 & Polrestra Padang & Jalan bungus teluk kabung km 15 & -1.0036184205307972 & 100.3874301945325 \\
\hline 5 & Poires Agam & jalan umum baran & 0.2608498027830852 & 99.96817455023527 \\
\hline 6 & Poires Agam & Jil tou km 5 & -0.42625682390503017 & 99.9629116196048 \\
\hline 7 & POLRESTA PAYANUMBUH & J Susiman & -0.20399696154898712 & 10064663987111237 \\
\hline
\end{tabular}

Gambar 7. Laporan Polres dan Polresta

\section{Kesimpulan}

Sistem Informasi Geografis (SIG) Titik Rawan Kecelakaan di wilayah Sumatera Barat dirancang dengan memanfaatkan Google Maps dan Google Service. Dengan data lokasi yang di input oleh masing-masing Polres Sumatera Barat, sistem akan menampilkan informasi daerah rawan kecelakaan berupa grafik, dan laporan perkabupaten serta menyajikan informasi lokasi Polres dan Polresta yang ada di Sumatera Barat. Pengguna juga dapat secara cepat mengetahui lokasi rawan kecelakaan dari jarak atau radius tertentu melalui Menu Pencarian Daerah Rawan Kecelakaan berdasarkan Posisi Pengguna. 


\section{Daftar Pusaka}

[1]. N. Rochmah Dyah P. A, dan E. Arsandy, "Sistem Informasi Geografis Tempat Praktek Dokter Spesialis di Provinsi D. I. Yogyakarta Berbasis Web," JSTIE., Vol.10, No 1, 2015.

[2]. A. Adil, "Pengertian Sistem Informasi Geografis", Sistem Informasi Geografis, Yogyakarta: Andi Offset, 2017, pp.3-4.

[3]. S. Maharani, D. Apriani, dan A. Harsa Kridaklaksana, "Sistem Informasi Geografis Pemetaan Masjid di Samarinda Berbasis Web,"Informatika., Vol.11, No.1, 2017.

[4]. Rastuti, L. Andretti Abdillah, dan E. Puji Agustini, "Sistem Informasi Geografis Potensi Wilayah Kabupaten Banyuasin Berbasis Web".pp. 53-58, August. 21-22. 2015.

[5]. Rastuti, L. Andretti Abdillah, dan E. Puji Agustini, "Pemodelan Daerah Rawan Kecelakaan Dengan Menggunakan Cluster Analysis (Studi Kasus: Kabupaten Boyolali)," Geodesi Undip., Vol.5, No1. 2016.

[6]. Akral," Mari Turunkan Tingkat Kecelakaan Di Sumatera Barat" [online]. Tersedia: http://www.sumbarprov.go.id/details/news/7278. 